\title{
Uf
}

Volume: 18 Issue: 4 Year: 2021

\section{An innovative approach to game- based learning in nursing education: Virtual gaming simulation}

\section{Hemşirelik eğitiminde oyun temelli öğrenmede yenilikçi bir yaklaşım: Sanal oyun simülasyonu}

\author{
Yadigar Ordu ${ }^{1}$ \\ Nurcan Çalışkan ${ }^{2}$
}

Özet

Hemşirelik eğitimi öğrencilere belirli rolleri üstlenmelerini sağlayacak düzeyde bilişsel, duyuşsal ve psikomotor öğrenim alanlarını içermektedir. Sınırlı klinik uygulamalar, hastaların öğrencilere uygulama yaptırmak istememesi ve öğretim elemanı sayısının az olması gibi nedenler ise öğrencilerin gelişimini olumsuz etkilemektedir. Bu nedenle yaşanan teknolojik gelişmeler hemşirelik eğitim müfredatına entegre edilerek öğrencilere bilgi ve beceri öğretimi daha güvenli ve etkin bir şekilde sağlanmaya çalışılmaktadır. Teknoloji çağında yetişen hemşirelik öğrencilerinin eğitiminde oyun temelli öğrenme giderek yaygınlaşmaktadır. Oyun temelli öğrenme, bilgide kalıcilığ1 sağlayarak aktif öğrenmeyi desteklemekte ve öğrenci memnuniyetini artırmaktadır. Son zamanlarda hemşirelik eğitiminde teknolojiyi içeren uygulamalardan biri sanal oyun simülasyonudur. Sanal oyun simülasyonu, öğrencilerin klinik bir senaryoya aktif katıllımını sağlayan, simüle edilmiş gerçek insanları içeren 2D (iki boyutlu) bir sanal bilgisayar oyunudur. Sanal simülasyon oyunları gerçeğe yakın senaryolar ile öğrencilerin klinik ortam1 deneyimlemesi, özgüvenlerinin, eleştirel düşünme ve klinik karar verme becerilerinin geliştirilmesi amacıyla tasarlanmıştır. $\mathrm{Bu}$

\footnotetext{
${ }^{1}$ Lecturer, Cankiri Karatekin University, Eldivan Vocational School of Health Services, Department of Health Care Services, yadigar usta ordu@hotmail.com (iD) Orcid ID: 0000-0002-4060-0487

2 Prof. Dr., Gazi University, Faculty of Health Sciences, Department of Nursing, nurcany@gazi.edu.tr (iD) Orcid ID: $0000-0001-9804-3030$
} 
Ordu, Y., \& Çalışkan, N. (2021). Hemşirelik eğitiminde oyun temelli öğrenmede yenilikçi bir yaklaşım: Sanal oyun simülasyonu. Journal of Human Sciences, 18(4), 657-664. doi:10.14687/jhs.v18i4.2021

which is a new approach in game-based learning in nursing education, and research on the subject.

Keywords: Educational technology; Gamebased learning; Nursing education; Nursing students; Virtual gaming simulation.

(Extended English summary is at the end of this document) makalenin amac1, hemşirelik eğitiminde oyun temelli öğrenmede yeni bir yaklaşım olan sanal oyun simülasyonunu ve konu ile ilgili yapilan araştırmaları açıklamaktır.

Anahtar Kelimeler: Eğitim teknolojisi; Hemşirelik eğitimi; Hemşirelik öğrencisi; Oyun temelli ögrrenme; Sanal oyun simülasyonu.

\section{GİRİŞ}

Hemşirelik eğitimi öğrencilere profesyonel rolleri üstlenmelerini sağlayabilecek düzeyde bilişsel, duyuşsal ve psikomotor öğrenim alanlarını kapsamalıdır. Günümüzde uygulama alanlarının kullanımının kısıtlanması, öğrenci sayısının artmasına rağmen öğretim elemanı kadrosunun az olması, klinik uygulamalarda öğrencilerin yeterli şekilde değerlendirilememesi, hastaların öğrenciler tarafindan kendisine dokunulmasını istememesi, öğrencilerin hastaya zarar verme korkusu, diğer sağlık disiplinleri ile yaşanan iletişim bozuklukları gibi sorunlar öğrencilerin edindikleri bilgi ve becerileri hasta bakımına yansıtmalarını engellemektedir. $\mathrm{Bu}$ sorunlara rağmen öğrenci hemşirelerden mezun olduklarında güvenli ve etkin bir bakım vermeleri istenmektedir (Atakoğlu et al., 2020; Biyik Bayram \& Caliskan, 2019; Wang \& Tahir, 2020). Bu nedenle, yeni teknolojik gelişmeler hemşirelik eğitim müfredatına entegre edilerek hemşirelik öğrencilerinde beceri öğretiminin daha güvenli bir şekilde gelişiminin sağlanmaya çalışılması gün geçtikçe daha da önem kazanmıştır (Şahin \& Başak, 2019). Günümüzde, Milenyum kuşağı olarak adlandırılan Z kuşağ1 öğrencileri; teknoloji ile iç içe dijital bir ortamda yetişmektedir. Teknoloji çağında yetişen hemşirelik öğrencileri geleneksel öğrenme yöntemleri ile pasif öğrenmeyi yeterli bulmamaktadır. Günümüz hemşirelik öğrencileri, bilgiye erişimde teknolojiyi etkin şekilde kullanmayı, anında geri bildirim almayı ve eğitime aktif katılmayı talep etmektedir (White \& Shellenbarger, 2018). Teknolojiyi içinde barındıran aktif öğrenme yöntemleri öğrencilerin memnuniyetini ve öğrenme düzeyini artırmaktadır. $\mathrm{Bu}$ nedenle öğrencilerin duyuşsal alanını harekete geçirebilecek video, ses, animasyon, grafik gibi aktif öğrenme yöntemlerinin hemşirelik eğitim müfredatına dahil edilme gerekliliği ortaya çıkmıştır. Hemşire eğitimciler, öğrencileri motive edecek ve dikkatini çekecek aktif öğrenme yöntemlerini kullanmak durumundadır (Boctor, 2013). Eğitimciler, oyun temelli eğitim yöntemleri ile öğrenmeyi ilgi çekici şekilde sunmalıdır (White \& Shellenbarger, 2018). Hemşirelikte eğitiminde kullanılan oyunlar, video simülasyonları, animasyonlar ve avatarlar gibi farklı teknolojik içeriklerle donatılmaktadır (Şahin \& Başak, 2019).

$\mathrm{Bu}$ makalenin amacı, hemşirelik eğitiminde oyun temelli öğrenmede yeni bir yaklaşım olan sanal oyun simülasyonunu ve konu ile ilgili yapılan araştırmaları açılamaktır.

\section{Hemşirelik Eğitiminde Oyun Temelli Öğrenme}

Hemşirelik eğitiminde oyun kullanımı 1980’li yıllara dayanmaktadır. Geçmiş dönemlerde oyunlar, geleneksel olarak öğrenmeden ziyade bir eğlenme yöntemi şeklinde görülmüştür (Boctor 2013). Eğitimde oyun kullanımı, öğrencilerin klinik uygulama becerilerini geliştirme amacıyla ortaya çıkmıştır (Koivisto et al., 2018). Oyunun eğitim amaçlı kullanılması için problem çözme, kurallara uyum sağlama, hedefler, kazanma kabiliyeti, eleştirel düşünme, geri bildirim ve eğlence gibi unsurları içermesi gerektiği belirtilmektedir (Gallegos, Tesar, Connor \& Martz, 2017).

Hemşirelik eğitiminde oyunlar; farmakoloji, gerontoloji gibi farklı birçok klinik alanla zenginleştirilerek kullanılmaktadır. Eğitimde oyun kullanılması, öğrencinin kendi gelişimini gözlemlemesine, geri bildirim almasına, ekip çalışmasına, iş birliğine uyum sağlamasına, yaparakyaşayarak öğrenmesine ve sosyalleşmesine yardımcı olur (Biyik Bayram \& Caliskan, 2019; White \& 
Ordu, Y., \& Çalışkan, N. (2021). Hemşirelik eğitiminde oyun temelli öğrenmede yenilikçi bir yaklaşım: Sanal oyun simülasyonu. Journal of Human Sciences, 18(4), 657-664. doi:10.14687/jhs.v18i4.2021

Shellenbarger, 2018). Ekip iş birliği hemşirelik uygulamalarında hayati önem taşımaktadır. Bu nedenle oyunlar gerçek hayatta olduğu gibi ekip rollerini yansıtmaktadır. Bu gibi etkinlikler öğrencinin motivasyonunu ve memnuniyetini artırmaktadır. Oyunlarda kazanılan başarının derecelendirilmesi, milenyum kuşağı olan hemşirelik öğrencilerinin kazandığı başarıyı onaylamasını ve geri bildirim almasını sağlayarak öğrenmeyi daha zevkli hale getirmektedir (Şahin \& Başak, 2019). Hemşirelik eğitiminde oyunların kullanılmasıyla; hasta veya klinik ekipman kullanmadan öğrenme, ekip çalısmasına katılma, eleştirel düşünme, karar verme ve problem çözme becerilerini geliştirme, teori ve uygulama arasındaki bağı güçlendirme, öğrenmeye aktif katılma, empati becerisini, iletişimi ve yaratıcılığ1 geliştirme, kendi hızına göre ilerleme, bireysel öğrenme, tekrar etme, bilgiyi test etme ve öğrencilerin klinik uygulama becerilerini geliştirme imkanları sağlanabilir (Biyik Bayram \& Caliskan, 2019; Koivisto et al., 2018; Şahin \& Başak, 2019).

Simülasyon oyunları, öğrencilerin klinik uygulama öncesinde bilgi, beceri ve tutum kazanmalarını sağlamaktadır. Ayrıca empati gibi soyut kavramların öğretilmesinde de etkili bir yöntem olduğu görülmektedir (Chen, Kiersma, Yehle \& Plake, 2015). Yapılan bir araştırmada, geriatri ilaç oyununun hemşirelik öğrencilerinin yaşlı bakımında empati becerisi kazandırdığ1 bildirilmiştir (Chen et al., 2015). Del Blanco ve arkadaşlarının (2017) simülasyon oyunu ile yaptıkları çalışmada, daha önce ameliyathane deneyimi olmayan tup ve hemşirelik öğrencilerinin oyun sayesinde hata yapmaktan daha az korktukları ve daha fazla iş birlikçi tutum sergiledikleri sonucuna ulaşılmıştır (Del Blanco et al., 2017). Hemşirelik esasları alanında geliştirilen bir oyunu, öğrenciler faydalı ve ilgi çekici bulup oyunun müfredata entegre edilmesi gerektiğini belirtmişlerdir (Boctor, 2013). Tan ve arkadaşlarının (2017) gerçekliği artırmak için avatarlar ekleyerek geliştirdikleri oyunda, hemşirelik öğrencilerinin kan transfüzyon uygulamasını yönetmesi beklenmektedir. Çalışmada, oyunun hemşirelik öğrencilerinde öğrenmeyi arttırdığı ve pedagojik bir yaklaşım olduğu belirlenmiştir (Tan et al., 2017). Johnsen ve arkadaşlarının (2016), KOAH’lı bireylerin bakımında problem çözme ve klinik karar verme becerilerini geliştirmek için hemşirelik öğrencilerine sunulan oyunun faydalı ve zevkli olduğu sonucuna ulaşılmıştır (Johnsen et al., 2016). Koivisto ve arkadaşlarının (2015) çalışmasında, hemşirelik süreci aşamalarını içeren sanal gerçeklik oyununun öğrencilerin tecrübelerini ve motivasyonlarını artırdığı bulunmuştur (Koivisto et al., 2015). Başka bir çalışmada dekontaminasyon öğretimi amacıyla geliştirilen oyun tabanlı sanal gerçeklik uygulamasının, öğrencilerin bilgi ve becerilerini artırdığı belirlenmiştir (Smith et al., 2016). Benzer şekilde Boada ve arkadaşları (2015) tarafindan kardiyopulmoner resusitasyon uygulamasına yönelik geliştirilen oyunun da öğrencilerin bilgi, beceri ve motivasyonlarını artırdığı bulunmuştur (Boada et al., 2015). Biyik Bayram \& Caliskan (2019) tarafindan yapılan araştırmada, oyun tabanlı sanal gerçeklik uygulamasının hemşirelik öğrencilerine trakeostomi uygulaması öğretiminde destek niteliğinde olduğu ve oyun kullanımının yararlı olacağı belirtilmiştir (Biyik Bayram \& Caliskan, 2019). Yapılan bir başka çalışmada ise ameliyathane oyununun öğrenmeye katkıda bulunduğu ancak tek başına eğitim yöntemi olarak kullanılamayacağı bulunmuştur (Paim \& Golmeier, 2017). Hemşirelik eğitiminde oyunların kullanılması henüz gelişme dönemindedir (Koivisto et al., 2018). Bu nedenle derleme, oyun temelli öğrenmede yenilikçi bir yaklaşım olan sanal oyun simülasyonunu ve konu ile ilgili araștırmaları açıklaması açısından özgündür.

Yapılan araştırmalara göre, hemşirelik eğitiminde özellikle beceri öğretiminde oyun kullanımının öğrencilerin bilgi, beceri ve motivasyonlarını artırdığı, ilgi çekici ve eğlenceli bir ortam oluşturarak aktif öğrenmeyi desteklediği ancak oyun kullanımının tek başına etkili bir yöntem olmadığı örgün eğitime destekleyici nitelikte kullanılmasının daha etkin olacağı görülmektedir.

\section{Hemşirelik Eğitiminde Sanal Oyun Simülasyonu}

Son zamanlarda, hemşirelik eğitiminde teknolojiyi içeren öğretim yöntemlerinden biri sanal oyun simülasyonudur. Sanal oyun simülasyonu, öğrencilerin klinik bir senaryoya aktif katılımını sağlayan, simüle edilmiş gerçek insanları içeren 2D (iki boyutlu) bir sanal bilgisayar oyunudur. Farklı klinik ortamlarda sanal hasta kullanarak merkezi bir role yerleştirilmiş olan öğrencilerin karar verme ve iletişim becerilerini kullanmasını sağlayan pedagojik bir stratejidir (Atthill, Witmer, Luctkar-Flude 
Ordu, Y., \& Çalışkan, N. (2021). Hemşirelik eğitiminde oyun temelli öğrenmede yenilikçi bir yaklaşım: Sanal oyun simülasyonu. Journal of Human Sciences, 18(4), 657-664. doi:10.14687/jhs.v18i4.2021

\& Tyerman, 2021; Verkuyl, Romaniuk, Atack \& Mastrilli, 2017a; Verkuyl ve ark., 2019a; Verkuyl ve ark., 2019b; Verkuyl, Atack, Kamstra-Cooper \& Mastrilli, 2020).

Sanal oyun simülasyonları, kullanıcıların sanal bir hasta için kritik hemşirelik yanıtını hemşirelik bilgisini kullanıp seçerek senaryoda bir yanıt vermesini gerektiren klinik senaryoyu içermektedir. Sanal oyunda, dallara ayrılan bir senaryo formatı kullanılır. Bu nedenle kullanıcının karar verme seçeneklerine göre dallanma senaryoları açılır. Hazırlanan senaryoya uygun şekilde aksiyon kamerası ile çekilen videolar klinik ortamın gerçek görüntülerini içerir. Görüntüler, hemşirenin bakış açısından alınır. Böylece, kullanıcı sanal oyun simülasyonunu oynarken hemşirenin rolünü somutlaştırır ve gözlemden ziyade klinik bir deneyim sağlar. Sanal simülasyon oyunlarında, kullanıcının belirli bir ortamdaki karakterle etkileşime girmesi ve belirli bir sonuca ulaşmak için karar vermesi beklenmektedir. Her karar noktasında kullanıcı, simüle edilmiş hastanın bir videosunu izler ve ardından bir dizi olası yanıt arasından tekrar seçim yapar. Kullanıcıya üç ya da dört adet yanıt seçeneği sunulur. Kullanıcı bir yanıtı seçtikten sonra, sonraki video bu seçimin etkisini gösterir. Her kararın ilgili modülde ilgili içerikle bir bağlantısı vardır. Doğru yanıt seçilirse, kullanıcı doğru yanıtın sonuçları görür. Oyunun devamında kullanıcıya başka karar noktaları sunulur ve seçilen her doğru yanıtla oyun devam eder. Yanlış bir seçim yapılırsa, oyunda bir geri bildirim görünür ve kullanıcıya farklı bir yanıt seçme firsatı verilir. Geri bildirimde yanlış seçilen yanıtın veya en doğru olmayan kararın gerekçesi sunulur. Böylece kullanıcının hasta için verdiği her klinik kararı deneyimlemesi sağlanır. Bu süreç, kullanıcı oyunu başarılı bir şekilde tamamlayana kadar devam eder. Oyunun sonunda kullanıc1, verdiği her kararın raporunu alır (Atthill et al., 2021; Padilha et al., 2019; Verkuyl et al., 2017a; Verkuyl, 2017b; Verkuyl, Romaniuk \& Mastrilli, 2018; Verkuyl et al., 2019a; Verkuyl et al., 2019b; Verkuyl et al., 2020).

Sanal simülasyon oyunları, öğrencileri gerçeğe yakın senaryolar ile yüz yüze simülasyon deneyimlerine hazırlamak, simülasyonla öğrenmeye bağlı bazı zorlukları hafifletmek, öğrencilerin bilgilerini arturmak, motive etmek, aktif öğrenmeyi desteklemek ve klinik uygulamaya geçme konusunda özgüvenlerini artırmak amacıyla tasarlanmıştır (Atthill et al., 2021; Verkuyl et al., 2020). Sanal oyun simülasyonlar1, klinik uygulama öncesinde hastaya zarar vermeden hatalar1 güvenli bir şekilde yapma ve yüksek riskli klinik durumları önceden deneyimle firsatı sağlamaktadır (Liu, 2021).

Tablo 1. Sanal oyun simülasyonunun teorik çerçevesi

\begin{tabular}{|c|c|c|c|}
\hline \multicolumn{4}{|c|}{ Oyunu başlat } \\
\hline $\begin{array}{l}\text { Dallanma senaryosu-1 } \\
\text { (En doğru olmayan } \\
\text { dallanma yanıtu) }\end{array}$ & $\begin{array}{l}\text { Dallanma senaryosu-2 } \\
\text { (En doğru olmayan } \\
\text { dallanma yanıtı) }\end{array}$ & $\begin{array}{l}\text { Dallanma senaryosu-3 } \\
\text { (En doğru dallanma } \\
\text { yanıtı) }\end{array}$ & $\begin{array}{c}\text { Dallanma senaryosu-4 } \\
\text { (En doğru olmayan } \\
\text { dallanma yanıtı) }\end{array}$ \\
\hline $\begin{array}{l}\text { Dallanma senaryosu } \\
\text { 1'e ilişkin simüle } \\
\text { edilmiş hasta videosu }\end{array}$ & $\begin{array}{l}\text { Dallanma senaryosu } \\
\text { 2'e ilişkin simüle } \\
\text { edilmiş hasta videosu }\end{array}$ & $\begin{array}{l}\text { Dallanma senaryosu } \\
\text { 3'e ilişkin simüle } \\
\text { edilmiş hasta videosu }\end{array}$ & $\begin{array}{l}\text { Dallanma senaryosu } \\
\text { 4'e ilişkin simüle } \\
\text { edilmiş hasta videosu }\end{array}$ \\
\hline $\begin{array}{l}\text { En doğru olmayan } \\
\text { kararın gerekçesine } \\
\text { yönelik kullanıciya geri } \\
\text { bildirim sunulur }\end{array}$ & $\begin{array}{l}\text { En doğru olmayan } \\
\text { kararın gerekçesine } \\
\text { yönelik kullaniciya geri } \\
\text { bildirim sunulur }\end{array}$ & Oyun devam eder & $\begin{array}{c}\text { En doğru olmayan } \\
\text { kararın gerekçesine } \\
\text { yönelik kullanıcıya geri } \\
\text { bildirim sunulur }\end{array}$ \\
\hline $\begin{array}{l}\text { Kullanıcının farklı bir } \\
\text { dallanma yanıtını } \\
\text { seçmesi istenir }\end{array}$ & $\begin{array}{l}\text { Kullanıcının farklı bir } \\
\text { dallanma yanıtını } \\
\text { seçmesi istenir }\end{array}$ & $\begin{array}{c}\text { Dallanma senaryosu- } \\
5,6,7,8 \text { kullaniciya } \\
\text { sunulur ve oyun } \\
\text { devam eder }\end{array}$ & $\begin{array}{l}\text { Kullanıcının farklı bir } \\
\text { dallanma yanıtını } \\
\text { seçmesi istenir }\end{array}$ \\
\hline \multicolumn{4}{|c|}{ Bu süreç, kullanıcı oyunu başarilı bir şekilde tamamlayana kadar devam eder } \\
\hline \multicolumn{4}{|c|}{ Oyunu bitir } \\
\hline
\end{tabular}


Ordu, Y., \& Çalışkan, N. (2021). Hemşirelik eğitiminde oyun temelli öğrenmede yenilikçi bir yaklaşım: Sanal oyun simülasyonu. Journal of Human Sciences, 18(4), 657-664. doi:10.14687/jhs.v18i4.2021

\section{Sanal Oyun Simülasyonlarının Hemşirelik Eğitiminde Kullanımı}

Hemşirelik öğrencileri, sanal oyun simülasyonlarının klinik deneyimi artırmada ve sınavlara hazırlık aşamasında oldukça yararlı olduğunu, yazılı vaka çalısmalarına göre gerçekçi bir ortam sağladığını belirtmişlerdir (Atthill et al., 2021; Padilha et al., 2019; Verkuyl et al., 2017a; Verkuyl et al., 2018; Verkuyl et al., 2020).

Konu ile ilgili yapılan araştırmalar incelendiğinde; Verkuyl ve arkadaşları (2017b), hemşirelik öğrencilerinin akıl sağllğı ve kişilerarası şiddet değerlendirmeleri yapmak için sanal oyun simülasyonu kullanma deneyimlerini araştırmıştır. Sanal oyun simülasyonu ile öğrenciler; güvenli, ilgi çekici ve gerçekçi bir ortamda becerilerini uygularken oyunun yeni bilgileri öğrenmelerine ve uygulamalarına olanak tanıdığını bildirmiştir (Verkuyl et al., 2017b). Yapılan bir araştırmada, sanal oyun simülasyonunu kullanan hemşire eğitimcilerin yaşadıkları zorluklar, oyunun faydaları ve eğitimcilerin oyuna yönelik önerilerini belirlemek amacıyla nitel araştırma yapılmıştır. Yapılan araştırmada hemşire eğitimciler, sanal oyunun öğrencileri klinik uygulamaya hazırladığını, çok yönlülüğü, etkililiği ve karar verme becerilerini artırdığını, etkileşimli öğrenmeyi sağladığını ve müfredata dikkatli bir şekilde uygulandığında oldukça etkili bir öğrenme stratejisi olabileceğini ifade etmişlerdir. Ayrıca, teknik sorunlar ile karşılaşıldığında öğrenci deneyiminin olumsuz etkilenebileceğini ve oyunun maliyet analizinin yapılması gerektiğini de belirtmişlerdir (Verkuly et al., 2020). Başka bir çalışmada, sanal simülasyon oyununu oynama formatının öğrenme deneyimini etkilediğini belirlenmiştir. Perinatal sanal simülasyon oyununu hemşirelik öğrencilerine bireysel, çift ve gruplar halinde oynatmışlardır. Bireysel oyun sırasında öğrenciler, hata yapmaktan korkmadan farklı seçenekleri keşfetme firsatını deneyimlemiştir. Çiftler ve gruplar halinde oynandığında ise hata yapma özgürlüğünün azaldığı, bazı öğrencilerin oyuna daha hakim olduğu ve bu durumun öğrenme deneyimini olumsuz etkilediği belirlenmiştir. Çalışmada, oyun oynarken en iyi formatın bireysel oyun ve ardından grup bilgilendirme olduğu sonucuna ulaşılmıştır (Verkuyl et al., 2019a). Verkuyl ve arkadaşları (2017a), hemşirelik öğrencilerinin pediatrik bilgilerinin geliştirilmesi amacıyla sanal oyun simülasyonu ile laboratuvar simülasyonu karşılaştırmıştır. Çalışmada, sanal oyun simülasyonu grubunda yer alan öğrencilerin öz yeterlik puanlarının laboratuvar simülasyonunda yer alan öğrencilere göre daha yüksek olduğu bulunmuștur (Verkuyl et al., 2017a). Atthill ve arkadaşlarının çalısmasında (2021), obstetrik sanal oyun simülasyonundan sonra sanal asenkron bilgi almanın hemşirelik öğrencilerinin klinik karar verme konusunda algılanan kaygılarını azalttığını ve klinik bir senaryo dahilinde uygulamanın öğrencilerin özgüvenlerini geliştirdiği bulunmuştur (Atthill et al., 2021). Liu (2021) sanal oyun simülasyonunun, hemşirelik öğrencilerinin psikiyatrik hastalıkları olan kişilere yönelik olumlu inançlarını ve tutumlarını güçlendirmek için etkili bir deneyimsel öğrenme aracı olarak kullanılabileceği sonucuna ulaşmıştır (Liu, 2021). Yapılan araştırmalarda sanal oyun simülasyonunun; hemşirelik öğrencilerinin etkileşimini, katılımını, geribildirimini, öz yeterlik algısını, memnuniyetini, eleştirel düşünme yeteneklerini, psikomotor ve karar verme becerilerini artırdığ1 belirlenmiştir (Atthill et al., 2021; Liu, 2021; Verkuyl et al., 2017a; Verkuyl et al., 2017b; Verkuyl et al., 2018; Verkuyl et al., 2019a; Verkuyl et al., 2020).

Yapılan çalışmalara göre, sanal oyun simülasyonunun hemşirelik öğrencilerinin klinik karar verme becerilerini, memnuniyetlerini ve öz yeterliklerini artırdığı, özgüvenlerini geliştirdiği, klinik kaygılarını azalttı̆̆ı, sanal oyunun bireysel kullanılmasının daha etkili olduğu ve teknik alt yapısının uygulama öncesinde değerlendirilmesinin kullanıcı memnuniyetini artırdığ1 görülmektedir.

\section{SONUÇ VE ÖNERİLER}

Yaşanan teknolojik gelişmeler birçok alanda etkili olduğu gibi eğitim süreçlerinde de etkisini göstermektedir. Günümüzde bilgi, beceri ve tutum sürekli olarak yenilenmekte ve bu durum hemşirelik eğitimini çağa uygun şekilde tasarlamayı gerekli kılmaktadır. Öğrenmeyi ilgi çekici hale getirmek amacıyla hemşire eğitimciler oyun temelli öğrenme yöntemlerini kullanmaktadır. Son zamanlarda hemşirelik eğitiminde kullanılan oyunlardan birisi sanal oyun simülasyonudur. Sanal oyun simülasyonları, öğrencilere gerçek bir klinik deneyim sağlaması 
Ordu, Y., \& Çalışkan, N. (2021). Hemşirelik eğitiminde oyun temelli öğrenmede yenilikçi bir yaklaşım: Sanal oyun simülasyonu. Journal of Human Sciences, 18(4), 657-664. doi:10.14687/jhs.v18i4.2021

açısından zamanla hemşirelik eğitimin müfredatına entegre edileceği öngörülmektedir. Günümüzde, sanal oyun simülasyonlarının hemşirelik eğitiminde kullanılmasına yönelik yapılan araştırmalar sınırlıdır. Bu nedenle hemşirelik eğitiminde sanal oyun simülasyonlarının kullanılabilirliğine ve uygulanmasına yönelik daha fazla araştırma yapılması önerilmektedir. Sanal oyun simülasyonlarının hemşirelik eğitiminde kullanılmasına bağlı avantajlar ve uzun vadede hemşirelik öğrencileri üzerine etkisi araştırma sonuçları ile daha net hale gelecektir.

\section{KAYNAKLAR}

Atakoğlu R, Asiye Gül, Türen S, Kıvanç MM, Özçalık CK. (2020). Hemşirelik Eğitiminde Simülasyon Kullanımının Önemi. Türkiye Sağlık Bilimleri ve Araştırmaları Dergisi, 3(2), 52-60.

Atthill S, Witmer D, Luctkar-Flude M, Tyerman J. (2021). Exploring the impact of a virtual asynchronous debriefing method after a virtual simulation game to support clinical decision$\begin{array}{llll}\text { making. Clinical } \quad \text { Simulation } & \text { 10 } 18 .\end{array}$ https://doi.org/10.1016/j.ecns.2020.06.008.

Biyik Bayram S, Caliskan N. (2019). Effect of a game-based virtual reality phone application on tracheostomy care education for nursing students: a randomized controlled trial. Nurse Education Today, 79, 25-31. https://doi.org/10.1016/j.nedt.2019.05.010.

Boada I, Rodriguez-Benitez A, Garcia-Gonzalez JM, Olivet J, Carreras V, Sbert, M. (2015). Using a serious game to complement CPR instruction in a nurse faculty. Computer Methods and Programs in Biomedicine, 122(2):282-291. https://doi.org/10.1016/j.cmpb.2015.08.006.

Boctor L. (2013). Active-Learning Strategies: The Use Of A Game To Reinforce Learning İn Nursing Education. A Case Study, Nurse Educ in Pract., 13 (2): 96-100. doi: 10.1016/j.nepr.2012.07.010.

Chen AM, Kiersma ME, Yehle KS, Plake KS. (2015). Impact of the Geriatric Medication Game ${ }^{\circledR}$ on nursing students' empathy and attitudes toward older adults. Nurse Education Today, 35(1), 38-43. https://doi.org/10.1016/j.nedt.2014.05.005.

Del Blanco Á, Torrente J, Fernández-Manjón B, Ruiz P, Giner M. (2017). Using a videogame to facilitate nursing and medical students' first visit to the operating theatre. A randomized $\begin{array}{llll}\text { controlled trial. Nurse } \quad \text { Education } & \text { Today, 55, 53. }\end{array}$ https://doi.org/10.1016/j.nedt.2017.04.026.

Gallegos C, Tesar AJ, Connor K, Martz K. (2017). The use of a game-based learning platform to engage nursing students: A descriptive, qualitative study. Nurse Education in Practice, 27, 101-106. https://doi.org/10.1016/j.nepr.2017.08.019.

Johnsen HM, Fossum M, Vivekananda-Schmidt P, Fruhling A, Sletebo A. (2016). A Serious Game for Teaching Nursing Students Clinical Reasoning, Stud Health Technol Inform, 225: 905906. doi: 10.3233/978-1-61499-658-3-905.

Koivisto JM, Niemi H, Multisilta J, Eriksson E. (2015). Nursing students' experiential learning processes using an online 3D simulation game. Education and Information Technologies, 22(1):383-398. doi: 10.1007/s10639-015-9453-x.

Koivisto JM, Haavisto E, Niemi H, Haho P, Nylund S, Multisilta J. (2018). Design Principles For Simulation Games For Learning Clinical Reasoning: A Design-Based Research Approach, Nurse Education Today, 60: 114-120. doi: 10.1016/j.nedt.2017.10.002.

Liu W. (2021). The Effects of Virtual Simulation on Undergraduate Nursing Students' Beliefs about Prognosis and Outcomes for People with Mental Disorders. Clinical Simulation in Nursing, 50, 1-9. https://doi.org/10.1016/j.ecns.2020.09.007.

Padilha JM, Machado PP, Ribeiro A, Ramos J, Costa P. (2019). Clinical virtual simulation in nursing education: randomized controlled trial. Journal of Medical Internet Research, 21(3), e11529. https://doi.org/10.2196/11529.

Paim CPP, Goldmeier S. (2017). Development of an educational game to set up surgical instruments on the Mayo stand or back table: Applied research in production technology. JMIR Serious Games, 5(1), e6048. https://doi.org/10.2196/games.6048. 
Ordu, Y., \& Çalışkan, N. (2021). Hemşirelik eğitiminde oyun temelli öğrenmede yenilikçi bir yaklaşım: Sanal oyun simülasyonu. Journal of Human Sciences, 18(4), 657-664. doi:10.14687/jhs.v18i4.2021

Smith SJ, Farra S, Ulrich DL, Hodgson E, Nicely S, Matcham W. (2016). Learning and retention using virtual reality in a decontamination simulation. Nursing Education Perspectives, 37(4):210-214. doi: 10.1097/01.NEP.0000000000000035.

Şahin G, Başak T. (2019). Hemşirelik Eğitiminde Oyun Temelli Öğrenme. Gümüşhane Üniversitesi Sağlık Bilimleri Dergisi, 8(3), 308-314.

Tan AJQ, Lee CCS, Lin PY, Cooper S, Lau LST, Chua WL, Liaw SY. (2017). Designing and evaluating the effectiveness of a serious game for safe administration of blood transfusion: A randomized controlled trial. Nurse Education Today, 55, 38-44. https://doi.org/10.1016/j.nedt.2017.04.027.

Verkuyl M, Atack L, Kamstra-Cooper K, Mastrilli P. (2020). Virtual gaming simulation: an interview study of nurse educators. Simulation \& Gaming, 51(4), 537-549. https://doi.org/10.1177\%2F1046878120904399.

Verkuyl M, Hughes M, Tsui J, Betts L, St-Amant O, Lapum JL. (2017b). Virtual gaming simulation in nursing education: A focus group study. The Journal of Nursing Education, 56(5), 274-280. https://doi. org/10.3928/01484834-20170421-04.

Verkuyl M, Lapum JL, St-Amant O, Hughes M, Romaniuk D, Mastrilli P. (2019b). Designing virtual gaming simulations. Clinical Simulation in Nursing, 32, 8-12. https://doi.org/10.1016/j.ecns.2019.03.008.

Verkuyl M, McGee N, McCulloch T, Tsui J, Layard B. (2019a). Different formats for playing virtual gaming simulations. CIN: Computers, Informatics, Nursing, 37(5), 237-240. doi: 10.1097/CIN.0000000000000539.

Verkuyl M, Romaniuk D, Atack L, Mastrilli P. (2017a). Virtual gaming simulation for nursing education: An experiment. Clinical Simulation in Nursing, 13(5), 238-244. https://doi.org/10.1016/j.ecns.2017.02.004.

Verkuyl M, Romaniuk D, Mastrilli P. (2018). Virtual gaming simulation of a mental health assessment: A usability study. Nurse Education in Practice, 31, 83-87. https://doi.org/10.1016/j.nepr.2018.05.007.

Wang AI, Tahir R. (2020). The effect of using Kahoot! for learning. A literatüre review. Computers \& Education 149, 103818. https://doi.org/10.1016/j.compedu.2020.103818.

White M, Shellenbarger T. (2018). Gamification of nursing education with digital badges. Nurse Educator, 43(2), 78-82. doi: 10.1097/NNE.0000000000000434.

\section{Extended English Summary}

Nursing education should include cognitive, affective and psychomotor fields of learning which will enable students to take on certain roles. Today, problems such as restrictions regarding the practice areas, the high number of students, the low number of instructors, the patients' unwillingness to allow students to conduct application on themselves, the communication problems with other health disciplines and the fear of harming the patient effect the development of the students. Despite these problems, a safe and effective care is expected from graduate nurses (Atakoglu et al., 2020; Biyik Bayram \& Caliskan, 2019; Wang \& Tahir, 2020). Therefore, the skills training of the nursing students who are raised in the digital environment embedded with technology, and who are referred to as the $\mathrm{Z}$ generation is tried to be supported by new technological developments for the skills training of the nursing students to be conducted in a more secure manner (Sahin \& Basak, 2019; White \& Shellenbarg, 2018). In this context, gamebased education methods have become a part of nursing education (White \& Shellenbarger, 2018). The use of games in nursing education has emerged to improve students' clinical practice skills (Boctor, 2013; Koivisto et al., 2018). In the researches, the use of games in nursing education contributes to students' individual development, team collaboration, individual learning, socialization, learning by practicing a strengthened bond between theory and practice, increased decision-making, skills of critical thinking and problem-solving, increasing motivation and satisfaction and the development of empathy, communication skills and creativity. (Biyik 
Ordu, Y., \& Çalışkan, N. (2021). Hemşirelik eğitiminde oyun temelli öğrenmede yenilikçi bir yaklaşım: Sanal oyun simülasyonu. Journal of Human Sciences, 18(4), 657-664. doi:10.14687/jhs.v18i4.2021

Bayram \& Caliskan, 2019; Boada et al., 2015; Chen et al., 2015; Del Balanco et al., 2017; Johnsen et al., 2016; Koivisto et al., 2018; Smith et al., 2016; Sahin \& Basak, 2019; Tan et al., 2017).

One of the teaching methods that includes technology in nursing education is virtual game simulation. Virtual game simulation is a $2 \mathrm{D}$ (two-dimensional) virtual computer game which enables students to actively participate in a realistic clinical scenario. The game uses a branching scenario format and real clinical scene footage. The user embodies the role of the nurse while playing the game and the game provides a clinical experience rather than observation. The user is expected to interact with the characters in a certain environment and make a decision in order to reach a certain result. For this reason, certain decision points consisting of three or four different options are presented to the user at certain time intervals. Branching scenarios become available / selectable based on the user's response. Following the correct answer, the game continues. When the wrong or the least correct response is given, a feedback appears in the game and the user is given the opportunity to choose a different answer. This process continues until the game is successfully completed. When the game is completed, the user receives a report of his decisions (Atthill et al., 2021; Padilha et al., 2019; Verkuyl, Romaniuk \& Mastrilli, 2018; Verkuyl et al., 2019a; Verkuyl et al., 2019b; Verkuyl et al., 2020). Virtual game simulations have been developed for obstetric, psychiatric and perinatal health, mental health and interpersonal violence, and in order to improve students' pediatric knowledge (Atthill et al. 2021; Liu 2021; Verkuyl et al., 2017b; Verkuyl et al., 2017b; Verkuyl et al., 2019b). It has been found that obstetric virtual game simulation reduces nursing students' anxiety and improves their self-confidence (Atthill et al., 2021). Liu (2021) determined in his study that virtual gaming is an effective experiential learning tool for students to develop positive attitudes and beliefs towards psychiatric patients. Verkuyl et al., (2017b) found that virtual game simulation in terms of mental health and interpersonal violence allowed students to attain and apply new knowledge in an interesting and realistic environment. In the study of Verkuyl et al., (2017a), it was found that the students in the virtual game simulation group had higher self-efficacy in pediatric skills development than the students in the laboratory simulation group. In another study, it was concluded that the best format for playing games was individual play, followed by a group information transfer (Verkuyl et al., 2019a). In a qualitative study, nurse educators reported that virtual games prepare students for clinical practice and provide interactive learning, but the cost analysis of the game must be carried out and technical problems which can occur may negatively affect learning (Verkuyl et al., 2020).

In the researches regarding virtual game simulation; It has been found that this kind of simulation contributed to individual and active learning, the development of students' clinical decision making, critical thinking and problem solving skills, the increase of motivation, satisfaction, self-confidence and self-efficacy, the development of empathy, communication skills, belief the improvement of attitude, creativity and the reduction of clinical anxiety. It has been concluded that virtual simulation games can be used in nursing education as effective experiential learning tools (Atthill et al., 2021; Liu, 2021; Verkuyl et al., 2017a; Verkuyl et al., 2017b; Verkuyl et al., 2018; Verkuyl et al., 2019a; Verkuyl et al., 2019b; Verkuyl et al., 2020). It is anticipated that virtual game simulation will be integrated into the nursing education curriculum over time in order to provide a realistic clinical experience. For this reason, it is recommended to conduct more research on the application of virtual game simulations in nursing education. With these researches, it is expected that the advantages of using virtual game simulations in nursing education and its effect on nursing students in the long run will become clearer. 